\title{
Polyphenol Composition and Antioxidant Activity of Different Potentially Functional Kale-Based Snacks
}

\author{
Filomena Nazzaro*, Federica Cardinale, Autilia Cozzolino, Tiziana Granese, \\ Florinda Fratianni \\ Institute of Food Science, ISA-CNR, Avellino, Italy \\ Email: ${ }^{*}$ mena@isa.cnr.it
}

Received 16 April 2014; revised 16 May 2014; accepted 24 May 2014

Copyright (C) 2014 by authors and Scientific Research Publishing Inc.

This work is licensed under the Creative Commons Attribution International License (CC BY). http://creativecommons.org/licenses/by/4.0/

(c) (i) Open Access

\begin{abstract}
Four types of kale-based snacks were investigated on the basis of polyphenol content and composition, glucosinolates amount, and antioxidant activity. The amount of polyphenols resulted to be higher than that of raw material, fresh kale $(0.57 \pm 0.03 \mathrm{mg} \mathrm{GAE})$. The antioxidant activity turned out indeed very effective, resulting sufficient just from $0.72 \mathrm{mg}$ to $2.1 \mathrm{mg}$ to dishearten the activity of $1 \mathrm{ml}$ DPPH to 50\%. Glucosinolates present in kale-based snacks ranged from $1.17 \mathrm{mg} / \mathrm{gr}$ to 1.52 mg of sinigrin equivalent/gr. Polyphenol profile, obtained by UPLC-DAD analysis allowed us to identify gallic acid, chlorogenic acid, and catechin common in all samples. Other polyphenols, that is caffeic acid, p-coumaric acid, and ferulic acid, were found in almost all samples, almost all more abundant than fresh kale, representing a precious source of beneficial metabolites. Our results suggest that such snacks could represent an effective functional dietary supplement also if compared to fresh vegetable. Manufacturing of kale-based snacks does not negatively affect the beneficial effect of the raw material; indeed, such snacks could positively meet people's expectation, mainly children and young, well known consumers of snacks, which, also in such manner, could be addressed towards a healthier dietary regime.
\end{abstract}

\section{Keywords}

Kale, Antioxidant, Polyphenols, Glucosinolates, UPLC

\section{Introduction}

The modern dietary life style is unfortunately represented, mainly among young people, by an increasing con-

"Corresponding author.

How to cite this paper: Nazzaro, F., Cardinale, F., Cozzolino, A., Granese, T. and Fratianni, F. (2014) Polyphenol Composition and Antioxidant Activity of Different Potentially Functional Kale-Based Snacks. Food and Nutrition Sciences, 5, $1145-1152$. http://dx.doi.org/10.4236/fns.2014.512124 
sumption of some fast foods, like snacks, which can represent a "bomb" in terms of energy, fat, salt and carbohydrates, and contain a very low amount of healthy ingredients. Such problem is dramatically relevant: nowadays, also some eastern countries, like China, are trying to fight, also through more information, the increase and diffusion of such "bad" food. Fast foods often have a greater energy density respecting both to home-prepared ones and to the Mediterranean diet, this last being characterized by a great consumption of fruit and vegetables; their regular consumption may thus contribute to surplus of energy intake. Epidemiological studies ascertained that regular consumption of fruits and vegetables may reduce the risk of chronic diseases [1]; such benefits are mainly attributable to their natural antioxidant content [2]. Modern consumers are increasingly interested in their personal health, expecting that food is "healthy" or capable of preventing illnesses. Snacks, always considered as a popular and convenient food, can represent a key in the improvement of new categories of foods [3], with large diffusion and meliorated nutritional values [4]. They might be considered a perfect food format to deliver fruit or vegetal-derived phenolic antioxidants. Recently, some western countries proposed on the market new types of snacks (chips or crackers), manufactured almost totally with green vegetables, like Brassicaceae, with proven health benefits. The family Brassicaceae (or Cruciferae) include different genera and thousands of species, of worldwide economic relevance. These vegetables possess beneficial properties, ascribable to the content of secondary metabolites, such as phenolics, vitamins and carotenoids [5], generally produced by plant against biotic and abiotic stress, and with well knowm antioxidant and anticarcinogenic properties. Furthermore, they provide a large group of glucosinolates, in which hydrolysis products can protect against cancer [6] [7]. Kale broccoli (Brassica oleracea var acephala) or Greek cauliflower, is one of the most ancient Brassica species developed in the eastern countries of the Mediterranean area. It has pulpy and curly dark green leaves and is much resistant to low temperatures. Kale may be prepared in the same way as spinach and its small amounts are used as a good component of salads. At our knowledge, there is not literature reporting the putative beneficial effect of kale when manufactured in unusual way than salads or soups, two of the most diffused manner of eating this vegetable. Kale is rich of antioxidants, and represents a good source of minerals, like Fe, Mn, S, Ph; kale contains a noticeable amount of highly bioavailable Ca (about 9\% of daily need) [8], as well as vitamins A, K and C. It has anticancer [9], anti-inflammatory [10] and hypocholesterolemic properties [11]; due to its high content of fibers and the absence of fat, kale has a very low content of calories. Thus, choice to use such raw matter for the production of these snacks can be very relevant from a functional viewpoint, taking also into account the high beneficial properties of kale on human health. Therefore, aim of our work was to evaluate the polyphenol composition, the glucosinlates amount and the antioxidant activity of four types of kale-based snacks (chips and crackers), much diffused in some markets of USA, Australia and Northern Europe.

\section{Materials and Methods}

All standards were provided from Sigma Chemicals (Milano, Italy). Acetonitrile, methanol, ultrapure water and trifluoroacetic acid were obtained from Carlo Erba Reagenti (Milano, Italy). All reagents were analytical grade.The work was performed on these types of Kale-based snacks, bought on local markets: "Inspiral kale" chips, containing: Kale (56\%), Wasabi mix (formed by raphanus, mustard,wasabi $1.4 \%$, spirulin, wheat $0.9 \%$, salt, pepper; "Yellow kale" chips, containing Kale, yellow sweet pepper, olive oil, salt; "Happy kale" snack, containing Kale, sunflower, seeds, water, coconut, carob, vanilla extract, salt; "Kale crackits" (like crackers), containing Kale, sunflower seed, carrot, buckwheat, almonds, olive oil, flax seed, garlic, salt

\subsection{Extraction of Polyphenols}

Samples were homogenized with 3 volumes of ethanol and kept at $4^{\circ} \mathrm{C}$ overnight, to avoid the extraction of glucosinolates, usually extracted with another procedure at hot temperatures (see later). The procedure was performed on a horizontal shaker. After centrifugation (11,600 × g, Biofuge, Beckmann, CA, USA), the supernatant was collected, dried and re-suspended in $3 \mathrm{ml}$ of sterile pure water.

\subsection{Colorimetric Analysis of Total Phenolics}

The total phenolic contents were determined following the method of Singleton \& Rossi [12] using the FolinCiocalteu phenol reagent. The absorbance at $\lambda=760 \mathrm{~nm}$ was determined at room temperature using a Cary UV/Vis spectrophotometer (Varian, Palo Alto, CA, USA). Quantification was based on a standard curve generated using gallic acid. The results were expressed as mg of gallic acid equivalent (GAE)/g of fresh weight (fw) 
of the product \pm standard deviation (SD).

\subsection{Free Radical Scavenging Capacity}

The free radical scavenging activity was determined using the stable radical 2,2-diphenyl-1-picrylhydrazyl (DPPH assay) [13]. The analysis was performed in microplates by adding $7.5 \mu \mathrm{L}$ of extract to $303 \mu \mathrm{L}$ of a methanol-DPPH solution $(153 \mathrm{mM})$. Next, the absorbance at $\lambda=517 \mathrm{~nm}$ was measured (Cary $50 \mathrm{MPR}$, Varian, USA). The absorbance of DPPH without antioxidant (control) was used for baseline measurements. The scavenging activity of the extract was expressed as the $50 \%$ effective concentration $\left(\mathrm{EC}_{50}\right)$, defined as the sample concentration (mg) necessary to inhibit the DPPH radical activity by $50 \%$ during a 60 -min incubation. These experiments were performed in triplicate, and the results are expressed as the mean values \pm standard deviation.

\subsection{Extraction of Glucosinolates}

The extraction of glucosinolates was performed following the method of Abdel-Farid et al. [14] with some modifications. 1 gr sample was mixed with methanol 70\% (rate 1:10 w/vol). Samples were vigorously mixed, heated for 10 minutes at $100^{\circ} \mathrm{C}$, mixed again and centrifuged (Biofuge, Beckmann, CA, USA) for 10 min at $6000 \mathrm{rpm}$ at $4^{\circ} \mathrm{C}$, to recover supernatant. Methanol $70 \%$ was added to the pellet, and the resulting mixture was kept overnight into the dark. The two supernatants were pooled and kept at $-25^{\circ} \mathrm{C}$ until the step of separation and analysis of glucosinolates.

\subsection{Separation and Analysis of Glucosinolates}

Arylsulfatase was prepared following the method of Graser et al. [15], dissolving the enzyme (70 mg) in $3 \mathrm{ml}$ of deionised water and $3 \mathrm{ml}$ of ethanol. Supernatant, recovered after centrifugation at $4000 \mathrm{rpm}$ for $5 \mathrm{~min}$ (Biofuge, Beckmann, CA, USA), was washed with ethanol $(9 \mathrm{ml})$ and centrifuged again. Pellet, containing purified enzyme, was then re-dissolved in ultrapure water. Separation of glucosinolates was performed using mini-columns containing Sephadex A25 previously activated with methanol 67\%. On each column $0.8 \mathrm{ml}$ of enzyme and $1 \mathrm{ml}$ of sample were charged. One side of the column was closed and columns were kept at room temperature overnight. Elution was performed using firstly $2 \mathrm{ml}$ of ultrapure water, then $2 \mathrm{ml}$ of methanol $60 \%$. Fractions were recovered and analyzed by HPLC, using a Gold System chromatograph equipped with an UV detector (Beckman, CA, USA). A Khromasil-KR100-5 C18 column $(25 \mathrm{~cm} \times 4.6 \mathrm{~mm})$ at room temperature was used for this analysis. The mobile phase included HPLC-grade water (containing $0.1 \%$ trifluoroacetic acid; solvent A) and 95\% acetonitrile (containing $0.1 \%$ trifluoroacetic acid; solvent B) in the following gradient system: initial $10 \%$ B, linear gradient to $50 \%$ B in 30 min, linear gradient to $100 \%$ B in 5 min, hold at $100 \%$ B for 2 min, decreasing gradient to $10 \%$ B in 2 min and coming back to the initial steps $10 \%$ B for 10 min [16]. The total pre-running and post-running time was $54 \mathrm{~min}$. The flow rate was $1 \mathrm{ml} / \mathrm{min}$, the injection volume was $20 \mu \mathrm{l}$, and the detection wavelength was set at $229 \mathrm{~nm}$. The areas of peaks were added together and quantified compared to the area of standard sinigrin. Glucosinolates were expressed in terms of mg sinigrin equivalent (SE)/gr sample.

\subsection{Chromatographic Analysis of Polyphenols}

Phenolics were analyzed using ultra performance liquid chromatography (UPLC). The extracts and the standards (previously dissolved in methanol) were filtered ( $0.45 \mu \mathrm{m}$, Waters, Milford, MA, USA) before analysis. UPLC analyses were performed using an ACQUITY Ultra Performance LC system (Waters) linked to a PDA 2996 photo diode array detector (Waters). Empower software was used to control the instruments, and for data acquisition and processing. The analyses were performed at $30^{\circ} \mathrm{C}$ using a reversed phase column $\left(\mathrm{BEH} \mathrm{C}_{18}, 1.7 \mu \mathrm{m}\right.$, $2.1 \times 100 \mathrm{~mm}$, Waters) following the method of Fratianni et al. [17]. The mobile phase consisted of solvent A (7.5 $\mathrm{mM}$ acetic acid) and solvent B (acetonitrile) at a flow rate of $250 \mu \mathrm{L} \cdot \mathrm{min}^{-1}$. Gradient elution was employed, starting with $5 \%$ B for $0.8 \mathrm{~min}$, then $5 \%-20 \%$ B over $5.2 \mathrm{~min}$, isocratic $20 \%$ B for $0.5 \mathrm{~min}, 20 \%-30 \%$ B for 1 min, isocratic $30 \%$ B for 0.2 min, 30\% - 50\% B over $2.3 \mathrm{~min}, 50 \%$ - 100\% B over $1 \mathrm{~min}, 100 \%$ B for 1 min, and finally $100 \%-5 \%$ B over $0.5 \mathrm{~min}$. At the end of this sequence, the column was equilibrated under the initial conditions for $2.5 \mathrm{~min}$. The pressure ranged from 6000 to $8000 \mathrm{psi}$ during the chromatographic run. The effluent was introduced into an LC detector (scanning range: 210 - $400 \mathrm{~nm}$, resolution: $1.2 \mathrm{~nm}$ ). The injection volume was $5 \mu \mathrm{L}$. 


\section{Results and Discussion}

The interest of finding natural antioxidants considerably increased since research has shown the impact that such compounds can exert on the management of a variety of clinical conditions and maintenance of health. Vegetable products are a good source of many biologically active antioxidant compounds [18]. Phenolic compounds, present in high concentration in human foods and beverages from plant and fruits, are potent blocking agents of $\mathrm{N}$-nitrosamine compound formation [19]. Phytophenolics can exhibit a positive effect in disease prevention, playing a crucial role in many mechanisms related to cell differentiation, inhibition of N-nitrosamine formation [20], deactivation of pro-carcinogens [21], and maintenance of DNA repair [22]. Vegetables, such as Brassica, are rich in bioactive compounds, including polyphenols, carotenoids and glucosinolates with proven positive effects on human health when consumed regularly [5] [9]. Lee et al. [23] observed a powerful antimutagenic activity of kale juice against aflatoxin B1. Table 1 lists the total phenolic content (expressed as mg of gallic acid equivalents, Panel A), the glucosinolates content (expressed as mg of sinigrin equivalents, Panel B), and the antiradical activity (expressed as $\mathrm{EC}_{50}$, Panel $\mathrm{C}$ ). On the whole, the four kale-based snacks exhibited a good content of polyphenols, ranging from $1.21 \mathrm{mg} / \mathrm{g}$ to $3.37 \mathrm{mg} / \mathrm{gr}$. Such finding let us hypothesize that the presence of sweet pepper and olive oil did not positively affect the content of polyphenols in yellow kale, which exhibited the lowest amount of polyphenols (1.21 mgGAE/gr). In all cases, the values were lower than those reported by Heimler et al. [24] which reported about $13.8 \mathrm{mg} \mathrm{GAE} / \mathrm{gr}$ of Italian kale; conversely, they resulted superior respect to the typical kale "torzella" of the Campania region (0.57 mgGAE/gr). Glucosinolates (GSs) are the main class of secondary metabolites found in cruciferous crops. They are formed by a thio-glucose moiety, a sulphonated moiety, and a variable side chain giving rise from an amino acid. GSs and their breakdown products (thiocyanates and isothiocyanates, nitriles and epithionitriles) have ascertained positive effects on human health, by exhibiting a blood protective effect against some types of cancer [25]-[27]. In vitro and in vivo studies showed that isothiocyanates affect many steps of cancer development including modulation of phase I and II detoxification enzymes [28]-[30]. Their presence is of particular relevance, taking into account, first of all, that such biomolecules can be easily degraded by stress technological processes, and mainly that, at the level of colon, they can be hydrolyzed by microbial enzymes, such as myrosinase, giving rise to the well known isothyocianates with anti-carcinogenic properties [31] [32]. Consequently, these compounds are attracting attention as potential chemo-protective agents against cancer. In our experiments, glucosinolates were analyzed by HPLC; their total amount was expressed in terms of mg sinigrin equivalent (SE)/gr of sample (Panel B, Table 1). All snacks showed high content of glucosinolates, ranging from $1.17 \mathrm{mg} \mathrm{SE} / \mathrm{gr}$ to $1.52 \mathrm{mg} \mathrm{SE} / \mathrm{gr}$. Although less abundant than in fresh kale (which exhibited $2.24 \mathrm{mg} \mathrm{SE} / \mathrm{gr}$, Panel B, Table 1), all snacks retained a good amount of glucosinolates, better preserved in yellow kale and crackits (1.52 mg SE/gr and $1.47 \mathrm{mg} \mathrm{SE} / \mathrm{gr}$, respectively), probably, in our opinion, due to the presence of olive oil. The high level of glucosinolates should not be related, in kale crackits, to the presence of carrot. Therefore, Shapiro et al. [33] demonstrated that the consumption of non-cruciferous (corn, tomatoes, green beans and carrots) did not lead to the excretion of dithiocarbamates, generally detected only after eating of cruciferous vegetables and condiments rich in isothiocyanates and/or glucosinolates. Moreover, the quantities of dithiocarbamates excreted were ascertained as related to the glucosinolate/isothiocyanate profiles and amount of the cruciferous vegetables administered (kale, broccoli, green cabbage, and turnip roots). The results of Shapiro et al. [33] established also that humans (and their gut microflora) convert substantial amounts of isothiocyanates and glucosinolates to dithiocarbamates that can be easily quantified. The antioxidant activity of samples was determined in terms of the their capability to inhibit the activity of

Table 1. Total Polyphenols (Panel A), Total glucosinolates (Panel B) and antioxidant activity (Panel C) of the four kalebased snacks The data are expressed as mean of three independent experiments \pm SD (Standard Deviation).

\begin{tabular}{cccc}
\hline & $\begin{array}{c}\text { A } \\
\text { Total polyphenols } \\
\text { (mg GAE/gr } \pm \text { SD) }\end{array}$ & $\begin{array}{c}\text { B } \\
\text { Total glucosinolates } \\
\text { (mg SE/gr } \pm \text { SD) }\end{array}$ & $\begin{array}{c}\text { C } \\
\text { Antioxidant activity } \\
\text { (mg EC }\end{array}$ \\
\hline Inspiral Kale \pm SD)
\end{tabular}


DPPH stable radical (Panel C, Table 1). All snacks were able to scavenge the radical, with $\mathrm{EC}_{50}$ values ranging from $0.72 \mathrm{mg} / \mathrm{ml}$ to $2.17 \mathrm{mg} / \mathrm{ml}$. The lowest activity was exhibited by yellow kale chips, although also its value is of remarkable value, occurring less than $2.5 \mathrm{mg}$ of its extract to inhibit DPPH at $50 \%$. In any case, the $\mathrm{EC}_{50}$ resulted always more effective than italian kale [24], which exhibited a $\mathrm{EC}_{50}$ of $92.91 \mathrm{mg}$, but very similar to a Southern Italy typical kale, the so called "Torzella riccia” $\left(\mathrm{EC}_{50}=1.53 \mathrm{mg}\right)$ [34]. Overall, taking into account the data about total polyphenols and glucosinolates, the antioxidant activity of snacks could be ascribable mainly to the total phenolic content than to glucosinolates. All kale-based snacks showed to be a potential important "mine", also in terms of specific polyphenols. UPLC polyphenols profile (Figure 1) lead to the detection of three common biomolecules in all kale snacks, although contained at different amount (Table 2): gallic acid, chlorogenic acid and catechin. The most abundant polyphenol in the snacks resulted (Table 2) chlorogenic acid, at concentration ranging from $431 \mu \mathrm{g} / \mathrm{gr}$ (Yellow Kale) to $1706 \mu \mathrm{g} / \mathrm{gr}$ (Happy Kale), and gallic acid, ranging from $94.7 \mu \mathrm{g} / \mathrm{gr}$ (Yellow Kale) to $448 \mu \mathrm{g} / \mathrm{gr}$ (Inspiral Kale). Chlorogenic acid reduces the risk of type II diabetes; the absorbed fraction of chlorogenic acid enters the blood and has positive effects on the cardiovascular system [35]. In vivo studies ascertained the antioxidant and anticarcinogenic properties of chlorogenic acid, which is usually poorly absorbed in the small intestine, but is conversely capable of providing higher yields of microbial metabolites, active compounds responsible for the biological properties attributed to dietary polyphenols [36]. The presence of catechin, although at minor concentration (ranging from $37 \mu \mathrm{g} / \mathrm{gr}$ to $72 \mu \mathrm{g} / \mathrm{gr}$, Table 2), may represent a further added value for the functional value of the kale-based snacks. Catechin is a plant flavonoid with non-toxic and liver-protective effects. This biomolecule is capable to inhibit the oxidation of low-density lipoprotein and to prevent human plasma oxidation [37]. Caffeic acid was found in yellow kale and kale crackits; p-coumaric acid, of remarkable value for its anti-inflammatory in vivo properties [38] was detected in almost all snacks (except yellow kale); its amount was particularly high in kale crackits. Ferulic acid was absent only in kale crackits, and resulted most abundant in inspiral kale. Other polyphenols were detected only in one of the snacks: epicatechin, was found only in inspiral kale; on the other hand, rutin was identified in yellow kale. Phenolics from cruciferous vegetables, such as flavonols (present in Brassica species), seemingly have protective properties against cardiovascular diseases and some types of cancer [39]. Although contained in minor amount and only in two of the snacks analyzed, the presence of these two biomolecules is very important, taking into account that they have the capability to protect low density lipoproteins against oxidation. Rutin is regarded as potent antioxidant with a broad spectrum of biological activities, including antioxidant, anti-inflammatory and immune-stimulating effects. The protective effect of rutin against different pro-carcinogens suggests other important biological activities for this compound, which can contribute to human health when incorporated into the diet [40]. Rutin is also capable to affect the NO synthesis by inhibition of NOS-2 and increase of endothelial NOS-3 activity [41]. Epicatechin can be easily absorbed (Yao et al., 2004) and reach different tissues, plasma, and the gut, where it not only inhibits the growth of some pathogens [42], but also can act as effective metal chelating and free radical scavenger, thereby considerably influencing the physiology of various mammalian cellular systems. Flavanols like epicatechin play a valuable effect opposed to a wide range of diseases from cardiovascular pathologies to cancer and degenerative conditions. The intake of epicatechin was ascertained to be inversely related to coronary heart disease [43]. Such molecules can be absorbed in the gastrointestinal tract and excreted, also through their metabolites. At intestinal level, microbiome split flavonoids eterocyclic ring which can be subsequently be degraded to phenolic acids; these last are subsequently absorbed, conjugated, excreted or further metabolized by bacteria, thus supplying the body of supplementary defense mechanisms against allergic reactions, inflammation, and in the prevention of cancer.

\section{Perspectives}

The future viability and success of functional foods in the marketplace depend on many factors. The key issue is consumer acceptance of such products. Functional snacks can represent one of the largest future area for functional food markets. Among the functional snacks, those made with vegetables, in this case with Brassicaceae stand out due to the inherently health benefits of polyphenols and glucosinolates, and to the beneficial changes occurring to the microbioma. Our results suggest that these kale-based snacks could represent an effective functional dietary supplement also if compared to fresh vegetable. Taking into account the biochemical characteristics of a fresh kale, like the Campania region typical "torzella" kale, which exhibited all polyphenols found in the four snacks analyzed [34], we can state that manufacturing of kale-based snacks does not negatively affect 

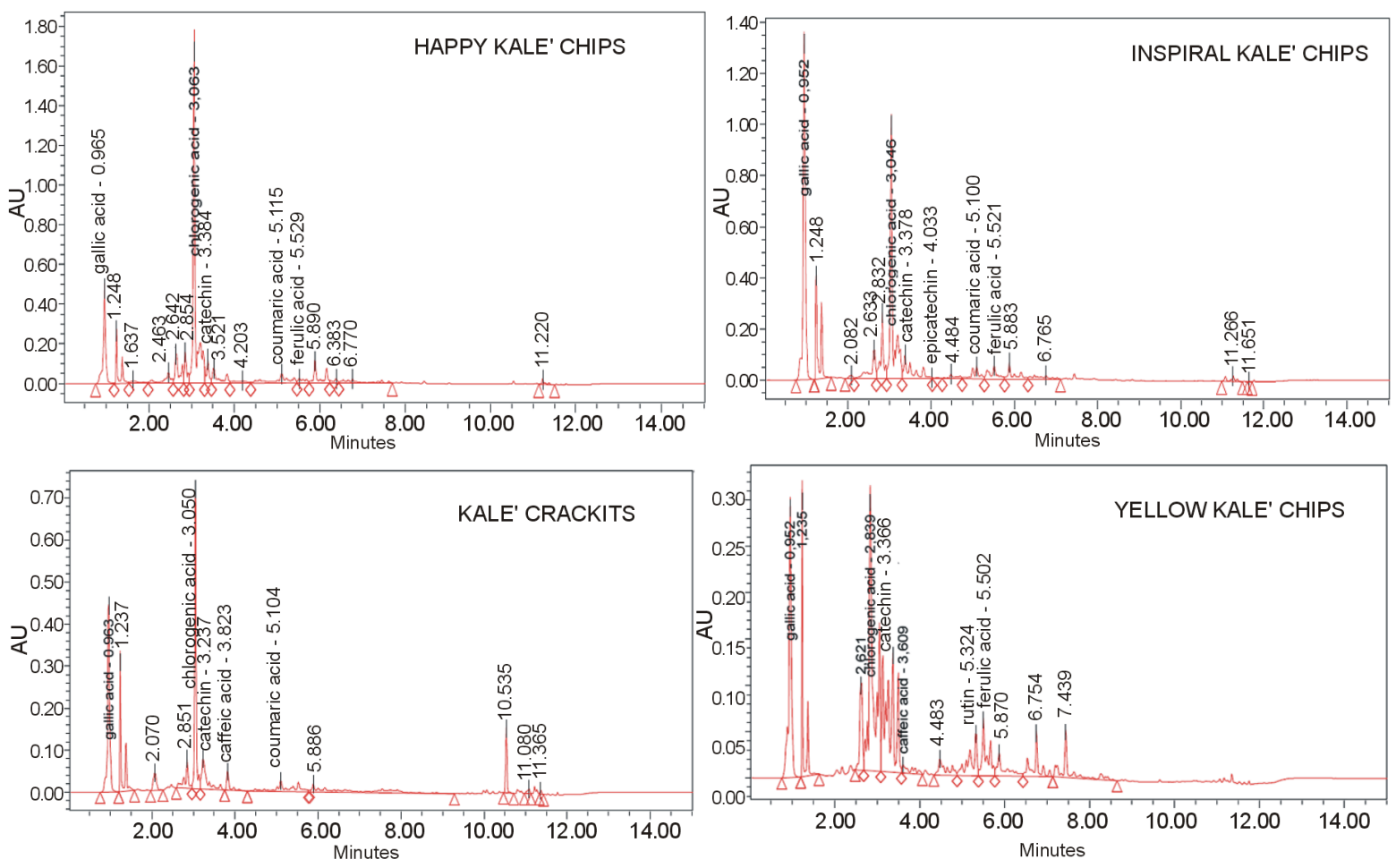

Figure 1. Polyphenol profile of the four kale-based snacks, obtained by UPLC analysis.

Table 2. Quantitative analysis of polyphenols present in the four Kale-based snacks, obtained through UPLC analysis. The data are expressed as $\mu \mathrm{g} \mathrm{GAE} / \mathrm{gr}$ of product.

\begin{tabular}{ccccc}
\hline & & UPLC analysis $(\mu \mathrm{g} / \mathrm{gr})$ & \\
\hline & HAPPY KALE' & INSPIRAL KALE' CHIPS & KALE' CRACKITS & YELLOW KALE' CHIPS \\
\hline Gallic acid & 182.51 & 447.67 & 330.32 & 94.70 \\
Chlorogenic acid & 1706.13 & 1012.00 & 945.04 & 431.39 \\
Catechin & 31.72 & 52.99 & 73.96 & 71.37 \\
Caffeic acid & - & - & 69.46 & 16.64 \\
Epicatechin & - & 18.12 & - & - \\
Coumaric acid & 34.65 & 15.64 & - & 193.44 \\
Rutin & - & - & - & 44.42 \\
Ferulic acid & 31.21 & 57.44 & & - \\
\hline
\end{tabular}

the beneficial effect of the raw material; indeed, the kale-based snacks might positively much more meet people's expectation, mainly children and young, well known consumers of snacks, which, also in such manner, could be addressed towards a more healthy dietary regime. New studies are expected to test other ingredients, to explore more options of food matrices which have not yet been industrially utilized, and to reengineer products and processes.

\section{Acknowledgements}

This research was partially funded by Project SALVE ("Safeguard of the vegetal genetic resources of the Campania region”), PSR 2007-2013, mis. 214, action f2, of the Campania Regional Council, Italy.

\section{References}

[1] Block, G., Patterson, B. and Subar, A. (1992) Fruit, Vegetables, and Cancer Prevention: A Review of the Epidemiological Evidence. Nutrition and Cancer, 18, 1-29. http://dx.doi.org/10.1080/01635589209514201 
[2] Bravo, L., Abia, R. and Saura-Calixto, F. (1994) Polyphenols as Dietary Fibre Associated Compounds. Comparative Study on in Vivo and in Vitro Properties. Journal of Agricultural and Food Chemistry, 42, 1481-1487. http://dx.doi.org/10.1021/jf00043a017

[3] Granato, D., Branco, G.F., Nazzaro, F., Cruz, A.G. and Faria, A.F. (2010) Functional Foods and Nondairy Probiotic Food Development: Trends, Concepts, and Products. Comprehensive Reviews in Food Science and Food Safety, 9, 292-302. http://dx.doi.org/10.1111/j.1541-4337.2010.00110.x

[4] Bhaskaran, S. and Hardley, F. (2002) Buyer Beliefs, Attitudes and Behaviour: Foods with Therapeutic Claims. Journal of Consumer Marketing, 19, 591-606. http://dx.doi.org/10.1108/07363760210451410

[5] Podsędek, A. (2007) Natural Antioxidants and Antioxidant Capacity of Brassica Vegetables: A Review. LWT-Food Science and Technology, 40, 1-11. http://dx.doi.org/10.1016/j.lwt.2005.07.023

[6] Cartea, M.E. and Velasco, P. (2008) Glucosinolates in Brassica Foods: Bioavailability in Food and Significance for Human Health. Phytochemistry Reviews, 7, 213-229. http://dx.doi.org/10.1007/s11101-007-9072-2

[7] Keum, Y.S., Jeong, W.S. and Kong, A.N.T. (2004) Chemoprevention by Isothiocyanates and Their Underlying Molecular Signaling Mechanisms. Mutation Research, 555, 191-202. http://dx.doi.org/10.1016/j.mrfmmm.2004.05.024

[8] Heaney, R.P., Weaver, C.M., Hinders, S.M., Martin, B. and Packard, P.T. (1993) Absorbability of Calcium from Brassica Vegetables: Broccoli, Bok Choy, and Kale. Journal of Food Science, 58, 1378-1380. http://dx.doi.org/10.1111/j.1365-2621.1993.tb06187.x

[9] Higdon, J.V., Delage, B., Williams, D.E. and Dashwood, R.H. (2007) Cruciferous Vegetables and Human Cancer Risk: Epidemiologic Evidence and Mechanistic Basis. Pharmacology Research, 55, 224-236. http://dx.doi.org/10.1016/j.phrs.2007.01.009

[10] Yoon, J.-H. and Baek, S.J. (2005) Molecular Targets of Dietary Polyphenols with Anti inflammatory Properties. Yonsei Medical Journal, 46, 585-596. http://dx.doi.org/10.3349/ymj.2005.46.5.585

[11] Kahlon, T.S., Chapman, M.H. and Smith, G.E. (2007) In Vitro Binding of Bile Acids by Spinach, Kale, Brussels Sprouts, Broccoli, Mustard Greens, Green Bell Pepper, Cabbage and Collards. Food Chemistry, 100, 1531-1536. http://dx.doi.org/10.1016/j.foodchem.2005.12.020

[12] Singleton, V.L. and Rossi Jr., J.A. (1965) Colorimetry of Total Phenolics with Phosphomolybdic-Phosphotungstic Acid Reagents. American Journal of Enology and Viticulture, 16, 144-158.

[13] Brand-Williams, W., Cuvelier, M.E. and Berset, C. (1995) Use of a Free Radical Method to Evaluate Antioxidant Activity. LWT_Food and Science Technology, 28, 25-30.

[14] Abdel-Farid, I.B., Jahangir, M., Mustafa, N.R., Van Dam, N.M., Cees, A.M., Van den Hondel, J.J., et al. (2010) Glucosinolate Profiling of Brassica rapa Cultivars after Infection by Leptosphaeria maculans and Fusarium oxysporum. Biochemical Systematics and Ecology, 38, 612-620. http://dx.doi.org/10.1016/j.bse.2010.07.008

[15] Graser, G., Oldham, N.J., Brown, P.D., Temp, U. and Gershenzon, J. (2001) The Biosynthesis of Benzoic Acid Glucosinolate Esters in Arabidopsis thaliana. Phytochemistry, 57, 23-32.

[16] Fratianni, F., Tucci, M., De Palma, M., Pepe, R. and Nazzaro, F. (2007) Polyphenolic Composition in Different Parts of Some Cultivars of Globe Artichoke (Cynara cardunculus L. var. scolymus (L.) Fiori). Food Chemistry, 104, 12821286. http://dx.doi.org/10.1016/j.foodchem.2007.01.044

[17] Fratianni, F., Coppola, R. and Nazzaro, F. (2011) Phenolic Composition and Antimicrobial and Antiquorum Sensing Activity of an Ethanolic Extract of Peels from the Apple Cultivar Annurca. Journal of Medicinal Food, 14, 957-963. http://dx.doi.org/10.1089/jmf.2010.0170

[18] Kiefer, I., Prock, P., Lawrence, C., Wise, J., Bieger, W., Bayer, P., et al. (2004) Supplementation with Mixed Fruit and Vegetable Juice Concentrates Increased Serum Antioxidants and Folate in Healthy Adults. Journal of American Collection of Nutrition, 23, 205-211. http://dx.doi.org/10.1080/07315724.2004.10719362

[19] Helser, M.A., Hotchkiss, J.H. and Roe, D.A. (1992) Influence of Fruit and Vegetable Juices on the Endogenous Formation of $\mathrm{N}$-Nitrosoproline and $\mathrm{N}$-Nitrosothiazolidine-4-Carboxylic Acid in Humans on Controlled Diets. Carcinogenesis, 13, 2277-2280. http://dx.doi.org/10.1093/carcin/13.12.2277

[20] Shahidi, F. (2004) Functional Foods: Their Role in Health Promotion and Disease Prevention. Journal of Food Science, 69, 146-149. http://dx.doi.org/10.1111/j.1365-2621.2004.tb10727.x

[21] Fratianni, F., Di Luccia, A., Coppola, R. and Nazzaro, F. (2007) Mutagenic and Antimutagenic Properties of Aqueous and Ethanolic Extracts from Fresh and Irradiated Tuber aestivum Black Truffle: A Preliminary Study. Food Chemistry, 102, 471-474. http://dx.doi.org/10.1016/j.foodchem.2006.04.014

[22] Kim, S.Y. (2012) Comparison of Nutritional Compositions and Antioxidant Activities of Building Blocks in Shinseoncho and Kale Green Vegetable Juices. Preventive Nutrition and Food Science, 17, 269-273. http://dx.doi.org/10.3746/pnf.2012.17.4.269 
[23] Lee, S.M., Park, K.Y. and Rhee, S.H. (1997) Antimutagenic Effect and Active Compound Analysis of Kale Juice in Salmonella Assay System. Journal of the Korean Society of Food Science and Nutrition, 26, 967-971.

[24] Heimler, D., Vignolini, P., Dini, M.G., Vincieri, F.F. and Romani, A. (2006) Antiradical Activity and Polyphenol Composition of Local Brassicaceae Edible Varieties. Food Chemistry, 99, 464-469. http://dx.doi.org/10.1016/j.foodchem.2005.07.057

[25] Rosa, E.A.S. (1999) Chemical Composition. In: Gomez-Campo, C., Ed., Biology of Brassicaceae Species, Elsevier Science B.V., Amsterdam, 315-357. http://dx.doi.org/10.1016/S0168-7972(99)80011-5

[26] Fahey, J.W., Zalcmann, A.M. and Talalay, P. (2001) The Chemical Diversity and Distribution of Glucosinolates and Isothiocyanates among Plants. Phytochemistry, 56, 5-51.

[27] Kassie, F., Uhl, M., Rabot, S., Grasl-Kraupp, B., Verkerk, R., Kundi, M., Chabicovsky, M., Schulte-Hermann, R. and Knasmüller, S. (2003) Chemoprevention of 2-amino-3-methylimidazo[4,5-f]quinoline (IQ)-Induced Colonic and Hepatic Preneoplastic Lesions in the F344 Rat by Cruciferous Vegetables Administered Simultaneously with the Carcinogen. Carcinogenesis, 24, 255-261. http://dx.doi.org/10.1093/carcin/24.2.255

[28] Cashman, J.R., Xiong, Y., Lin, J., Verhagen, H., Van Poppel, G., Van Bladeren, P.J., Larsen-Su, S. and Williams, D.E. (1999) In Vitro and in Vivo Inhibition of Human Flavin-Containing Monooxygenase Form 3 (FMO3) in the Presence of Dietary Indoles. Biochemical Pharmacology, 58, 1047-1055. http://dx.doi.org/10.1016/S0006-2952(99)00166-5

[29] Finley, J.W. (2005) Proposed Criteria for Assessing the Efficacy of Cancer Reduction by Plant Foods Enriched in Carotenoides, Glucosinolates, Polyphenols and Selenocompounds. Annals of Botany, 95, 1075-1096. http://dx.doi.org/10.1093/aob/mci123

[30] Smith, T.K., Lund, E.K., Clarke, R.G., Bennett, R.N. and Johnson, I.T. (2005) Effects of Brussels Sprout Juice on the Cell Cycle and Adhesion of Human Colorectal Carcinoma Cells (HT29) in Vitro. Journal of Agriculture and Food Chemistry, 53, 3895-3901. http://dx.doi.org/10.1021/jf048025v

[31] Tierens, K.F., Thomma, B.P., Brower, M., Schmidt, J., Kistner, K., Porzel, A., Mauch-Mani, B., Cammue, B.P.A. and Broekaert, W.F. (2001) Study of the Role of Antimicrobial Glucosinolate-Derived Isothiocyanates in Resistance of Arabidopsis to Microbial Pathogens. Plant Physiology, 125, 1688-1699. http://dx.doi.org/10.1104/pp.125.4.1688

[32] Hullar, M.A.J., Burnett-Hartman, A.N. and Lampe, J.W. (2014) Gut Microbes, Diet, and Cancer. Advances in Nutrition and Cancer, 159, 377-399.

[33] Shapiro, T.A., Fahey, J.W., Wade, K.L., Stephenson, K.K. and Talalay, P. (1998) Human Metabolism and Excretion of Cancer Chemoprotective Glucosinolates and Isothiocyanates of Cruciferous Vegetables. Cancer Epidemiology, Biomarkers \& Prevention, 7, 1091-1100.

[34] Fratianni, F., Cardinale, F., Cozzolino, A., Granese, T., Pepe, S., Riccardi, R., Spigno, P., Coppola, R. and Nazzaro, F. (2014) Polyphenol Composition and Antioxidant Activity of Two Autochtonous Brassicaceae of the Campania Region, Southern Italy. Food and Nutrition Science, 5, 66-70. http://dx.doi.org/10.4236/fns.2014.51009

[35] Johnston, K.L., Clifford, M.N. and Morgan, L.M. (2003) Coffee Acutely Modifies Gastrointestinal Hormone Secretion and Glucose Tolerance in Humans: Glycemic Effects of Chlorogenic Acid and Caffeine. American Journal of Clinical Nutrition, 78, 728-733.

[36] Gonthier, M.P., Verny, M.A., Besson, C., Remesy, C. and Scalbert, A. (2003) Chlorogenic Acid Bioavailability Largely Depends on Its Metabolism by the Gut Microflora in Rats. Journal of Nutrition, 133, 1853-1859.

[37] Lapis, K., Jeney, A., Divald, A., Vajta, G., Zalatnai, A. and Schaff, Z. (1986) Experimental Studies on the Effect of Hepatoprotective Compounds. Tokai Journal of Experimental and Clinical Medicine, 11, 135-145.

[38] Luceri, C., Guglielmi, F., Lodovici, M., Giannini, L., Messerini, L. and Dolara, P. (2004) Plant Phenolic 4-Coumaric Acid Protects against Intestinal Inflammation in Rats. Scandinavian Journal of Gastroenterology, 39, 1128-1133.

[39] Beecher, C.W.W. (1994) Cancer Preventive Properties of Varieties of Brassica Oleraceae: A Review. American Journal of Clinical Nutrition, 59, 1166S-1170S.

[40] Marcarini, J.C., Stefanini, M., Tsuboy, F., Cabral, L.R., Ribeiro, L.R., Hoffmann-Campo, C.B. and Mantovani, M.S. (2011) Investigation of Cytotoxic, Apoptosis-Inducing, Genotoxic and Protective Effects of the Flavonoid Rutin in HTC Hepatic Cells. Experimental and Toxicologic Pathology, 63, 459-465. http://dx.doi.org/10.1016/j.etp.2010.03.005

[41] Olszanecki, R., Gebska, A., Kozlovski, V.I. and Gryglewski, R.J. (2002) Flavonoids and Nitric Oxide Synthetase. Journal of Physiology and Pharmacology, 53, 571-584.

[42] Parkar, S.G., Stevenson, D.E. and Skinner, M.A. (2008) The Potential Influence of Fruit Polyphenols on Colonic Microflora and Human Gut Health. International Journal of Food Microbiology, 124, 295-298. http://dx.doi.org/10.1016/j.ijfoodmicro.2008.03.017

[43] Boyer, J. and Liu, R.H. (1994) Apple Phytochemicals and Their Health Benefits. Nutrition Journal, 3, 1-15. 
Scientific Research Publishing (SCIRP) is one of the largest Open Access journal publishers. It is currently publishing more than 200 open access, online, peer-reviewed journals covering a wide range of academic disciplines. SCIRP serves the worldwide academic communities and contributes to the progress and application of science with its publication.

Other selected journals from SCIRP are listed as below. Submit your manuscript to us via either submit@scirp.org or Online Submission Portal.
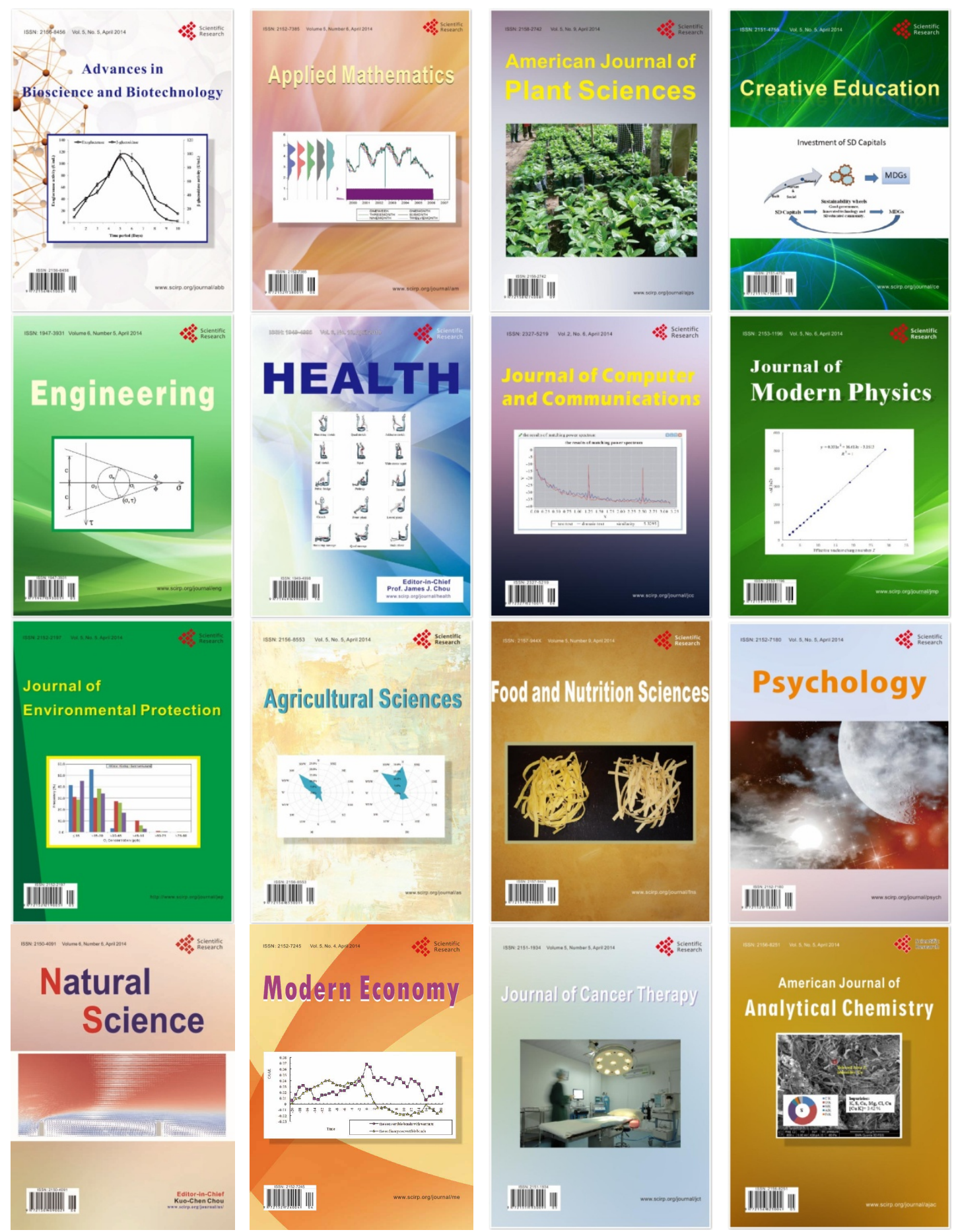